\title{
A comparative study of the timecourse of the expression of the thermo-inducible HSP70 gene in clinical and environmental isolates of Aspergillus fumigatus
}

\author{
GOLNAZ SHARAFI $^{1}$, ALI REZA KHOSRAVI ${ }^{1}$, GHASEM VAHEDI ${ }^{1}$, \\ RAMAK YAHYARAEYAT $^{1}$ and TEIMUR ABBASI ${ }^{2}$ \\ ${ }^{1}$ Mycology Research Center, Faculty of Veterinary Medicine, University of Tehran, Tehran 1419963111; \\ ${ }^{2}$ Faculty of Dentistry, Tabriz University of Medical Sciences, Tabriz 5166614711, Iran
}

Received August 4, 2015; Accepted March 15, 2016

DOI: $10.3892 / \mathrm{mmr} .2016 .5058$

\begin{abstract}
The internal environment within animals or humans provides different conditions to invading saprophytic fungal pathogens, requiring the differential regulation of genes in comparison to environmental conditions. Understanding the mechanisms by which pathogens regulate genes within the host may be key in determining pathogen behavior within the host and may additionally facilitate further investigation into novel therapeutic agents. The heat shock protein (HSP)70 gene and its associated proteins have been frequently reported to be among the most highly expressed and dominant proteins present within various locations at physiological temperatures. The present study examined relative gene expression levels of the HSP70 gene in Aspergillus fumigatus isolates from both clinical and environmental origins, at a range of temperature points $(20,30$, 37 and $42^{\circ} \mathrm{C}$ ) over five days, using reverse transcription-quantitative polymerase chain reaction, comparing with a standard A. fumigatus strain incubated at $25^{\circ} \mathrm{C}$. The results indicated a differential gene expression pattern for the environmental and clinical isolates. During the five days, the HSP70 expression levels in the clinical samples were higher than in the environmental samples. However, the difference in the expression levels between the two groups at $42^{\circ} \mathrm{C}$ was reduced. The mean HSP70 expression level over the five incubation days demonstrated a gradual and continual increasing trend by temperature elevation in both groups at 30,37 and $42^{\circ} \mathrm{C}$, however, at $20^{\circ} \mathrm{C}$ both groups demonstrated reduced expression. The temperature shift from 20 to $42^{\circ} \mathrm{C}$ resulted in HSP70 induction and up to a 10- and 8.6-fold change in HSP70 expression levels on the fifth day of incubation in the clinical and environmental groups,
\end{abstract}

Correspondence to: Dr Ghasem Vahedi, Mycology Research Center, Faculty of Veterinary Medicine, University of Tehran, Azadi Street, Tehran 1419963111, Iran

E-mail: g_vahedi@yahoo.com

Key words: Aspergillus fumigatus, heat shock protein 70, clinical, environmental, timecourse respectively. In conclusion, incubation at 37 and $42^{\circ} \mathrm{C}$ resulted in the highest expression levels in both experimental groups, with these temperature points important for the induction of HSP70 expression in A. fumigatus.

\section{Introduction}

Aspergillus fumigatus is a filamentous saprophyte and opportunist fungi spread ubiquitously in the environment (1). It is a leading cause of mold fungal infections in immune-compromised patients (2), and is a key allergen that is frequently accompanied by severe asthma, allergies and sinusitis (1,3-5). The spores are usually eradicated by the innate immune system response in lung epithelial tissue in immune-competent host, however, immune-compromised individuals are at risk for invasive Aspergillosis as a result of increasing spore loads in the lungs or other tissues (6). One of the most important reasons why A. fumigatus is able to infect avian and mammalian hosts is its thermotolerance capability (7). A. fumigatus is able to grow rapidly at $37^{\circ} \mathrm{C}$ and has been known as thermotolerant microbial agent (8). It has likely evolved mechanisms and intracellular pathways of thermal resistance similar to thermophilic fungi. A family of critically important gene expressed at high temperatures are the heat shock proteins (HSPs), which are a vital defense in challenged cells (9). Immediately following heat stress or in hyperthermic conditions, heat shock transcription factor (HSF) activates the transcription of a series of genes encoding HSPs (10-12). HSPs have been characterized as highly conserved molecular chaperones in evolutionary studies $(13,14)$. In addition, it was noted that their expression levels are increased under various stress conditions (15). It has been shown that the HSP70 family of proteins contains minor molecular sequence differences which enables them to adapt to new environmentally imposed situations (16). Chaperones, in particular HSP70, have been frequently reported as an immuno-dominant response to fungal infections, and described as a highly conserved family of $\sim 10$ proteins with a molecular mass of approximately $70 \mathrm{kDa}$ (17). Regarding HSPs as critical microbial defense mechanisms in stressed or high-temperature situations, such as those occurring within the host, research in this field has 
great potential to increase the clinical and scientific knowledge regarding how $\mathrm{HSP} 70$ is expressed at $37^{\circ} \mathrm{C}$ or higher as an approach to design novel specific therapeutics.

The present study focused on the HSP70 expression pattern over longer durations in A. fumigatus. The aim of the current study was to simulate the thermal conditions that occur when fungi inhabit the host body or environment. Additionally, the study aimed to explore the potential differences and expression patterns of HSP70 mRNA between clinical and environmental samples of A.fumigatus at various low and high temperatures over a longer duration. A longer experimental duration was established in the present study to find possible differential gene expression patterns in comparison to shorter study durations that have been previously reported.

\section{Materials and methods}

Strains and growth conditions. A total of 13 samples were collected by broncho-alveolar lavages or direct blood cultures from medically diagnosed Aspergillus infections caused by A.fumigatus in human and animal cases. In the case of human patients, sampling was conducted once informed consent was obtained and for animal cases, the ethical instructions of our institutions for animal handling and specimen collection were followed. The present study was approved by the ethics committee of Faculty of Veterinary Medicine, University of Tehran (Tehran, Iran). Additionally, following a series of environmental random sampling, six further A. fumigatus-identified isolates were incorporated in the study for use in further experiments. Furthermore, a standard A.fumigatus strain (ATCC ${ }^{\circledR}$ 90906; American Type Culture Collection, Manassas, VA, USA) was obtained and incorporated into the experiments. This gave a total of seven samples from humans and six samples from animals, plus six additional fresh samples from the environment (three from food and three from air) and a standard strain, which were cultured directly on general media in optimal conditions for fungal growth. Briefly, to purify and enrich the fungal isolates, fungi were cultured on sabouraud dextrose agar (Merck Millipore, Darmstadt, Germany) and incubated at $30^{\circ} \mathrm{C}$ for three days. The medium contained chloramphenicol ( $0.05 \%$ w/v; Merck Millipore) and cyclohexamide $(0.05 \% \mathrm{w} / \mathrm{v}$; Merck Millipore) to prevent the growth of bacteria and dermatophytic fungi. Subcultures were avoided and immediately following the growth of fungi and morphological, physiochemical and molecular identification, the fungal conidia were collected using Tween 80 to trap conidia. Briefly, the surface of the fungal culture plates were washed by sterile phosphate-buffered saline containing $0.02 \%$ Tween 80 , and the collected fluid was centrifuged for 5 min at $5,000 \mathrm{x}$ g and $4^{\circ} \mathrm{C}$ to concentrate the conidia. Collected conidia were counted using a hematocytometer. To induce the exponential/developmental phase of fungal hyphal growth and produce a biomass of $A$. fumigatus mycelia, a series of inoculations of yeast extract peptone dextrose (YPD) liquid medium (Merck Millipore) were prepared using A.fumigatus conidia for each clinical and environmental sample with three biological replicates at a final concentration of $1 \times 10^{6}$ conidia $/ \mathrm{ml}$ and incubated at $20,30,37$ and $42^{\circ} \mathrm{C}$ for five days. The standard strain was also cultured by the described method for five days at $25^{\circ} \mathrm{C}$, according to the manufacturer's instructions.
Total RNA Extraction. Floating A. fumigatus mycelia in YPD broth medium were harvested every $24 \mathrm{~h}$ for each temperature by filtration through Whatman paper. Harvested mycelia were washed with sterile water and then freeze-dried and ground using a mortar and pestle containing liquid nitrogen. Total RNA was obtained using TRIzol ${ }^{\circledR}$ Reagent RNA preparation method (Invitrogen; Thermo Fisher Scientific, Inc., Waltham, MA, USA) according to the manufacturer's protocol. Following precipitation, the RNA was resuspended in a $60 \mu 1$ RNAase-free tube. Contaminating genomic DNA was removed from RNA samples by treating with $1 \mu \mathrm{l}$ of RNAse-free DNase (SinaClon, Co., Tehran, Iran) for $30 \mathrm{~min}$ at room temperature. DNase was removed using a clean-up kit (SinaClon, Co.,). RNA integrity and the quantity of total RNA were measured using a NanoDrop 2000 (Thermo Fisher Scientific, Inc.).

Reverse transcription-quantitative polymerase chain reaction $(R T-q P C R)$. The RT-qPCR reaction was carried out using EvaGreen which is a modified version of SYBR green fluorescent DNA-binding dye in two steps. First, $2 \mu \mathrm{g}$ of purified RNA was used to synthesize first strand cDNA using a cDNA synthesis kit, which included an engineered reverse transcriptase to resist high temperatures providing increased specificity and higher yields of cDNA, in a final volume of $25 \mu 1$. Oligo-dT primers were used for the reverse transcription of protein-coding mRNAs. DEPC-treated water used to avoid RNA degradation. Prior to the addition of reverse transcriptase, the reaction mixture was incubated at $65^{\circ} \mathrm{C}$ for $5 \mathrm{~min}$ to denature RNA, and to avoid RNA secondary structures reforming, immediately chilled on ice. cDNA synthesis was initiated by an engineered Moloney Murine Leukemia Virus reverse transcriptase (SuperScript ${ }^{\circledR}$ III First-Strand synthesis kit; Invitrogen; Thermo Fisher Scientific, Inc.) at $50^{\circ} \mathrm{C}$ for $50 \mathrm{~min}$. The transcription reaction was stopped by heating the tubes to $85^{\circ} \mathrm{C}$ for $5 \mathrm{~min}$. Synthesized cDNA was immediately used to perform the PCR amplification procedure using a routine protocol to check the specificity of the primers and avoid homo- or hetero-dimer problems. qPCR gene-specific primers were incorporated in the reaction. The remaining cDNAs were stored at $-20^{\circ} \mathrm{C}$ until further use.

A qPCR kit (Jena Bioscience GmbH, Munich, Germany) with EvaGreen as the fluorescent dye was used to perform the qPCR assay. A total of $5 \mu \mathrm{l} \mathrm{cDNA}, 0.4 \mu \mathrm{M}$ of each forward and reverse primer, molecular-grade water and $12.5 \mu 1$ ready to use EvaGreen qPCR reagent in a final volume of $20 \mu \mathrm{l}$ were used to perform the qPCR reaction using a Rotor Gene $\mathrm{Q}$ real-time PCR system (Qiagen $\mathrm{GmbH}$, Hilden, Germany). For each sample and for their relative reference gene, the qPCR reaction was performed in three technical replicates. The cycling conditions were as follows: Initial denaturation and polymerase activation, $95^{\circ} \mathrm{C}$ for $2 \mathrm{~min}$; denaturation, $95^{\circ} \mathrm{C}$ for $15 \mathrm{sec}$; annealing, $55^{\circ} \mathrm{C}$ for $30 \mathrm{sec}$; extension, $72^{\circ} \mathrm{C}$ for $30 \mathrm{sec}$; amplification cycles, 45 cycles; final extension, $72^{\circ} \mathrm{C}$ for $5 \mathrm{~min}$; and melting curve analysis, a range between 45 - and $95^{\circ} \mathrm{C}$ with $0.2^{\circ} \mathrm{C}$ increments. The melting-curve analysis cycle was set to test for the existence of possible primer-dimers or other unspecific products. Primers for HSP70 in A. fumigatus were designed (Table I) using Primer-BLAST online software (http://www.ncbi.nlm.nih.gov/tools/primer-blast/) which uses both Primer3 and BLAST algorithms. Primers were 
designed to span exon-exon junctions to avoid the amplification of possible genomic DNA contamination. Additionally, an option to allow primers to amplify mRNA splice variants was also enabled to make the primers capable of amplifying all transcript variants and isoforms of the HSP70 gene. A reference mRNA sequence retrieved from the GenBank database (XM_745397) was selected to design the A.fumigatus HSP70 specific primers, as it is near identical to the Afulg07440 sequence from the Aspergillus Genome Database (AspGD). The BLAST online tool was used to check the similarity of the XM_745397 reference sequence to the orthologous heat inducible HSP70 genes in Aspergillus and other fungal species. Primers were designed for $18 \mathrm{~S}$ ribosomal RNA (rRNA) to be used as the reference gene, using Primer-BLAST with its default settings (Table I). The designed primers were also checked for possible secondary structures in order to avoid unexpected structures such as homo- \& hetero-dimers, using an online oligo-nucleotide analysis tool (IDT OligoAnalyzer 3.1; https://www.idtdna.com/calc/analyzer) (18). In addition, to check whether primers were able to amplify the target and reference gene cDNAs, a series of conventional PCR assays was performed. The PCR products were run on $1.5 \%$ agarose electrophoresis gels in TBA buffer $(0.45 \mathrm{M}$ Tris-Borate and $0.001 \mathrm{M}$ ethylenediaminetetraacetic acid) at $80 \mathrm{~V}$ for $90 \mathrm{~min}$. Gels were stained with ethidium bromide $(0.5 \mu \mathrm{g} / \mathrm{ml})$ and photographed using UV light in a gel documentation system (G:Box; Syngene, Cambridge, UK).

Statistical analysis and comparative $C_{q}$ method. MedCalc software, version 12 (MedCalc Software, Oostende, Belgium) (19) was used for statistical analysis. The Kolmogorov-Smirnov and normal probability plot indicated the data was normally distributed thus, two-tailed Student's t-test was used to test for significant differences between means. Tukey's test was used for multiple comparisons among several time points. The $\alpha$-level was set at 0.05 , thus $\mathrm{P}<0.05$ was considered to indicate a statistically significant difference. The mean, median and 95\% confidence interval (CI) of data were calculated using MedCalc software, version 12 (MedCalc Software bvba, Ostend, Belgium). Three specimens were collected from air and three from food and, to avoid statistical bias due to small sample size, all six were considered together as samples in a single environmental group. Expression fold changes and relative expression differences between experimental groups were calculated using $2^{-\Delta \Delta \mathrm{Cq}}$ method, which is additionally known as the comparative $\mathrm{C}_{\mathrm{q}}$ or Livak method (20). In this method, the efficiency of both the target gene and reference gene are assumed to be $100 \%$. The mathematical calculations of the method are based on the normalization of the quantification cycle $(\mathrm{Cq})$ values of both the sample and control groups to a reference gene, to prevent a cDNA amount input error, then the subtraction of the $\mathrm{Cq}$ values of the two experimental groups from each other, prior to the logarithmic transform of the resulting fold change values, to avoid misinterpreting the expression differences between the evaluated groups. The fold change values for each temperature point and experimental day in the sample groups were presented as graphs relative to the control group (A. fumigatus ATCC 90906 standard strain) expression level on the same day. The formula for the comparative $\mathrm{C}_{\mathrm{q}}$ method is as follows:
Relative expression fold change $=2^{-[(\text {meanCq of target gene in sample }}$ or treated group-meanCq of reference gene in sample or treated group)-(meanCq of target gene in control or untreated group-meanCq of reference gene in control or untreated group)].

\section{Results}

HSP70 primers and cDNAs were used in conventional PCR reactions, resulting in the detection of HSP70 expression in the different samples. The clinical samples exhibited clearly detectable bands following gel electrophoresis (Fig. 1). Additionally, at all the temperatures except, at the fifth day of incubation at $42^{\circ} \mathrm{C}$, relative expression of HSP70 mRNA in clinical samples was significantly higher compared with the environmental samples (Table II). There was a 2 -fold change in the expression levels normalized to the 18S RNA reference gene in the comparison of clinical and environmental samples at all temperatures during all experiment days, except at $37^{\circ} \mathrm{C}$ and $42^{\circ} \mathrm{C}$, where the majority of environmental samples exhibited smaller differences in expression levels compared with expression levels in the clinical samples (Fig. 2). There was no significant difference in HSP70 mRNA levels between clinical and environmental samples at the fifth day of incubation at $42^{\circ} \mathrm{C}$. Among all the experimental temperature points, the least significant difference in HSP70 expression levels was observed between clinical and environmental groups at $42^{\circ} \mathrm{C}$ (Table II). In detail, from the six environmental samples, four samples $(66.6 \%)$ at $42^{\circ} \mathrm{C}$ exhibited relatively competitive levels of expression compared with clinical samples. However, except for the fifth day, significant differences in the mean expression levels compared with the clinical samples at $42^{\circ} \mathrm{C}$ were observed for all incubation days (subgroup data not shown), however, the P-values at $42^{\circ} \mathrm{C}$ were higher than the P-values at the other higher temperature points (Table II). HSP70 mRNA levels in the environmental samples at the fourth and fifth days of incubation at $37^{\circ} \mathrm{C}$ and $42^{\circ} \mathrm{C}$ was closer to the HSP70 expression levels in the clinical samples in comparison with the expression levels at the first three days of incubation. Notably, one environmental strain demonstrated significantly lower expression levels of HSP70 mNRA at all temperatures, even at $42^{\circ} \mathrm{C}$ compared with the clinical samples. This strain was detected as an outlier in the confidence interval calculations and is indicated in the box-whisker plot as a separate data point (Fig. 3). Additionally, the expression levels of the environmental group at 37 and $42^{\circ} \mathrm{C}$ was significantly higher compared with the expression levels at lower temperature points $(\mathrm{P}<0.05$, Tukey's test). Furthermore, despite the mentioned high levels of expression at $37^{\circ} \mathrm{C}$ in the environmental group, differences in the expression levels between the clinical and environmental groups at this temperature were significant. By contrast, the clinical samples showed a marked increase in HSP70 expression, in particular at 37 and $42^{\circ} \mathrm{C}$, with an up to 10 -fold increase compared with the reference gene. Of note, on the first day at $20^{\circ} \mathrm{C}$, the clinical samples showed an upregulation of HSP70, while over the following days, in both clinical and environmental samples, the HSP70 gene was downregulated (Fig. 2). However, at $30^{\circ} \mathrm{C}$, the clinical samples demonstrated an upregulation of HSP70 mRNA levels at all five days. Additionally, the clinical samples on the first day at $20^{\circ} \mathrm{C}$ demonstrated expression levels greater than on the second day. In fact, HSP70 expression at $30^{\circ} \mathrm{C}$ in the clinical samples showed an initial reduction on the second day, however, gradually increased over the subsequent days. The 
Table I. Primer sequences used.

\begin{tabular}{llcccc}
\hline Gene & Direction & Sequence & $\begin{array}{c}\text { Length } \\
(\mathrm{bp})\end{array}$ & $\begin{array}{c}\text { Amplicon size } \\
(\mathrm{bp})\end{array}$ & $\begin{array}{c}\text { Source } \\
\text { accession no. }\end{array}$ \\
\hline 18S rRNA & Forward & 5'-TCAGGGAACGAAAGTTAGGG-3' & 20 & 107 & AB008401 \\
& Reverse & 5'-CGAGCGGGTCATCATAGAAA-3' & 20 & & \\
\multirow{2}{*}{ HSP70 } & Forward & 5'-GCCATTGCCTACGGTCTTG-3' & 19 & 225 & XM_745397 \\
& Reverse & 5'-GGTGAGATCCTTCTTGTGCTT-3' & 21 & & \\
\hline
\end{tabular}

bp, base pair; rRNA, ribosomal RNA; HSP70, heat shock protein 70.
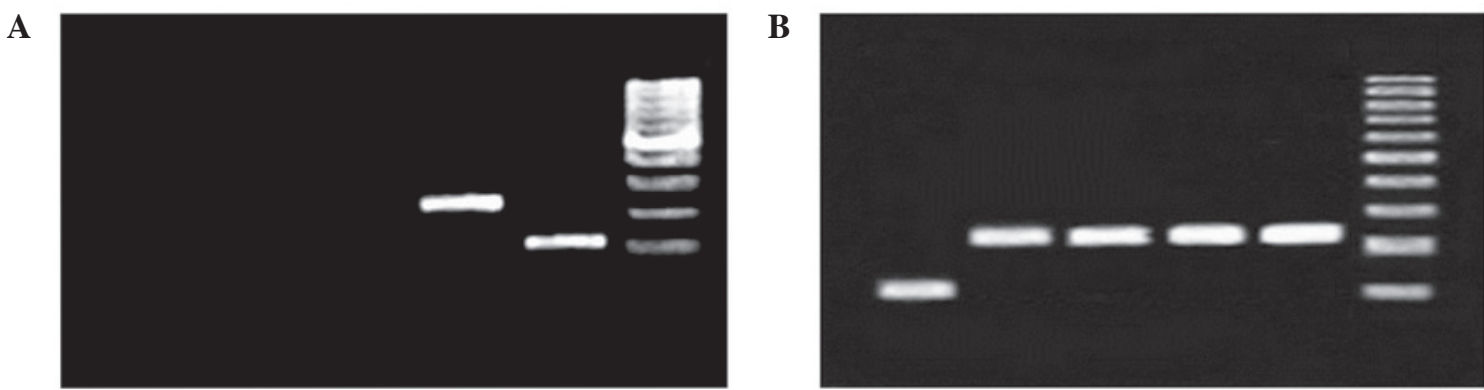

Figure 1. Gel electrophoresis image of PCR reaction using heat shock protein 70 primers and cDNA template demonstrate the lack of genomic DNA contamination and the correct binding of the primers. (A) PCR reaction using cDNA from an environmental sample at different temperatures. Only $42^{\circ} \mathrm{C}$ results in a detectable band on gel electrophoresis. From left to right: Lane 1, environmental sample at $20^{\circ} \mathrm{C}$; lane 2, environmental sample at $30^{\circ} \mathrm{C}$; lane 3 , environmental sample at $37^{\circ} \mathrm{C}$; lane 4 , environmental sample at $42^{\circ} \mathrm{C}$; lane $5,18 \mathrm{~S}$ rRNA; and lane 6 , ladder. (B) PCR products from a clinical sample. From left to right: Lane 1 , $18 \mathrm{~S}$ rRNA; lane 2 , clincal sample at $20^{\circ} \mathrm{C}$; lane 3 , clincal sample at $30^{\circ} \mathrm{C}$; lane 4 , clincal sample at $37^{\circ} \mathrm{C}$; lane 5 , clincal sample at $42^{\circ} \mathrm{C}$; and lane $6,1 \mathrm{kilo}$ base ladder. PCR, polymerase chain reaction; rRNA, ribosomal RNA.

environmental samples demonstrated downregulation compared with the control group during the first three days of incubation at $30^{\circ} \mathrm{C}$, however, their expression levels were increased compared with the mRNA levels at $20^{\circ} \mathrm{C}$ (Fig. 2). In contrast to the results obtained at 20 and $30^{\circ} \mathrm{C}$, a continual ascending pattern of HSP70 expression was observed for both the clinical and environmental samples at 37 and $42^{\circ} \mathrm{C}$ (Figs. 2 and 3). Furthermore, a considerable peak was observed at $37^{\circ} \mathrm{C}$ in the majority of the clinical samples during the five experimental days (Fig. 2). The expression levels in the clinical samples at $20^{\circ} \mathrm{C}$ on the first day were high, however, from day two demonstrated represented a significant reduction in expression, following which it exhibited a gradual reduction until the last day. By contrast, at $30^{\circ} \mathrm{C}$ both groups demonstrated an increasing trend. This was additionally observed at 37 and $42^{\circ} \mathrm{C}$ during the five experimental days. However, the increase at $37^{\circ} \mathrm{C}$ in $\mathrm{HSP} 70$ expression, particularly in the clinical samples which have the most considerable slope, indicates an instant increase and high levels of HSP70 expression (Figs. 2 and 3). This increase had an impact on the P-values at $37^{\circ} \mathrm{C}$, resulting in the most significant P-values among the other temperatures (Table II). Furthermore, from the 13 clinical samples, four demonstrated relative expression as low as the environmental samples at 20 and $30^{\circ} \mathrm{C}$. In addition, one other clinical sample demonstrated significantly higher expression at $42^{\circ} \mathrm{C}$ alone, in comparison to the environmental samples. However, seven samples $(53.8 \%)$ from the total 13 clinical samples exhibited significantly greater expression at all temperatures when compared with the mean expression levels of the environmental samples. Of the total 13 clinical isolates, at $42^{\circ} \mathrm{C}$ just one isolate expressed HSP70 with no significant difference compared with HSP70 expression in the environmental isolates (data not shown). These results indicate that 37 and $42^{\circ} \mathrm{C}$ are major temperatures responsible for the upregulation of HSP70 mRNA expression (Fig. 3). Furthermore, among the clinical isolates there were no significant differences in HSP70 expression between human- and animal- originated samples (data not shown). Overall, a continually increasing trend in HSP70 mRNA expression levels was observed in the increasing temperatures over the five days (Figs. 3 and 4). Evaluating the expression trend using a timecourse revealed that both the clinical and environmental samples demonstrated an increasing pattern of HSP70 mRNA expression levels at 30,37 and $42^{\circ} \mathrm{C}$, however, a reduction at $20^{\circ} \mathrm{C}$ (Figs. 3 and 4 ).

\section{Discussion}

Temperature fluctuations are common in the environment, and unstable thermal conditions may result in downstream alterations in the transcription levels of stress-related genes such as HSPs in environmental and opportunistic microbial agents. Microbial agents have evolved protective mechanisms in the face of harmful heat stress induced in diverse environmental conditions and host bodies (21). Long-term maintained high temperatures may lead microbes or host cells towards a lethal cascade of the denaturation of proteins which are vital for cells and microbes. In fact, during periods of elevated temperature, HSPs are the predominant proteins synthesized in fungal cells (22). 
Table II. P-values from two-tailed Student's t-test between the expression levels in the clinical and environmental groups at each temperature point over the five experimental days.

Culture temperature $\left({ }^{\circ} \mathrm{C}\right)$

\begin{tabular}{lllll}
\cline { 2 - 4 } Culture day & \multicolumn{1}{c}{20} & 30 & 37 & 42 \\
\hline One & 0.006 & 0.0033 & 0.0002 & 0.0004 \\
Two & 0.002 & 0.0175 & 0.0011 & 0.0017 \\
Three & 0.0025 & 0.0175 & 0.0053 & 0.0046 \\
Four & 0.003 & 0.011 & 0.01 & 0.044 \\
Five & 0.0037 & 0.013 & 0.027 & 0.2 \\
\hline
\end{tabular}

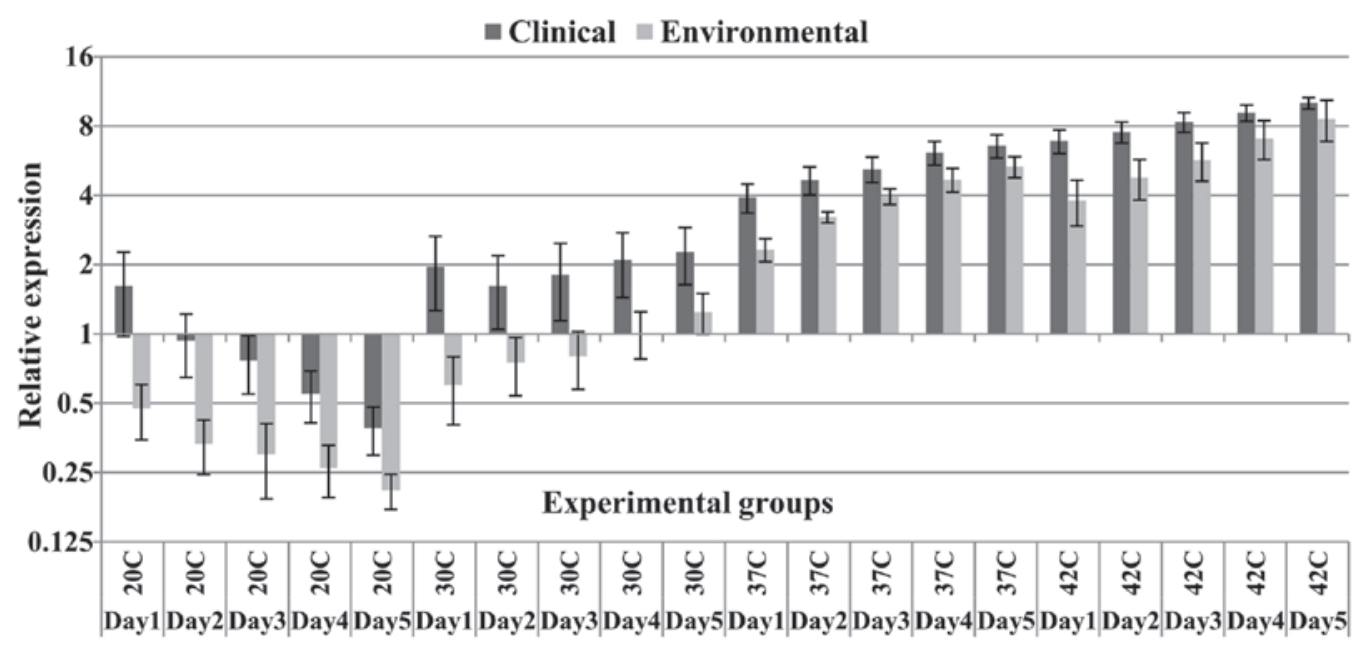

Figure 2. HSP70 relative expression levels over the five experimental days in the clinical and environmental groups indicated an ascending pattern at high temperatures. $\log 2$ transformation of HSP70/18S rRNA relative gene expression means using the $2^{-\triangle \Delta C q}$ method in the clinical and environmental groups over five days at $20,30,37$ and $42^{\circ} \mathrm{C}$ temperatures. Error bars are presented as the means \pm standard deviation. HSP70, heat shock protein 71 ; rRNA, ribosomal RNA; C, celsius.

In yeasts and other opportunist pathogenic fungi, thermal adaptation is not only essential to maintain thermal homeostasis, but is also required for virulence $(23,24)$. High temperatures in the host body is an inducer of virulence factors and HSPs, however, disparate observations in the virulence ability have been reported in mutation-studies of thermotolerance-related genes in fungal pathogens, indicating no direct association between thermophily and virulence traits, except in a few genes $(23,25-29)$. However, HSPs are essential for the survival of eukaryotic cells even under normal conditions. In this regard, the activation of thermal adaptation pathways in fungal cells has additionally been observed at mild temperature variations in host bodies (30). Thus, it may be hypothesized that the transcription of heat stress-related genes in clinically and host body-adapted pathogens may be regulated differentially in comparison with environmental microbial agents.

A. fumigatus is a common mold pathogen in human, and produces large amounts of proteins and enzymes when invading host bodies. The accumulation of damaged, unfolded or aggregated proteins in a pathogen may threaten its survival. Thereby, unfolded proteins act as a cellular thermometer (31,32), and in Saccharomyces cerevisiae there are four sub-families of genes encoding HSP70: $S s a, S s b, S s c$ and $S s d$ (22). Three location-dependent protective pathways have been described in S. cerevisiae, a yeast fungus, with all three pathways activated in response to injured proteins. When unfolded proteins accumulate in the endoplasmic reticulum, yeast cells express $K A R 2$ chaperone and $H A C l$. In the case of unfolding proteins in the cytosol, SSA4, the major HSP70 chaperone, is induced. In addition, the SSA4-HSP70 pathway is activated following heat shock (32). Another mechanism initiated by damaged proteins is the activation of a distinct set of genes in the Rpn4-dependent pathway (33).

It has been demonstrated that in yeast, the $S s a 1$ and $S s a 2$ genes are constitutively expressed while $\mathrm{Ssa} 3$ and $\mathrm{Ss} a 4$ are upregulated under stressed situations (34). Currently, eight HSP70 homologues have been identified, of which six are cytosolic including Ssa1, Ssa2, Ssa3, Ssa4, Ssb1 and Ssb2 (9,35). In comparison to the Ssa genes, Ssb1 and Ssb2 differentially regulate Hsf1 activity in yeast (36). It has additionally been indicated that Ssb1/2p is not induced by heat shock (37). In the current study, primers were designed to investigate the mRNA expression levels of HSP70 in A. fumigatus, using a reference sequence obtained from the GenBank database. According to the information in GenBank and AspGD (38), the sequences were similar or orthologous to the SSA2 gene in Candida albicans, S. cerevisiae, Schizosaccharomyces pombe and to the HSP70-1 gene in Neurospora crassa. Furthermore, BLAST searches 


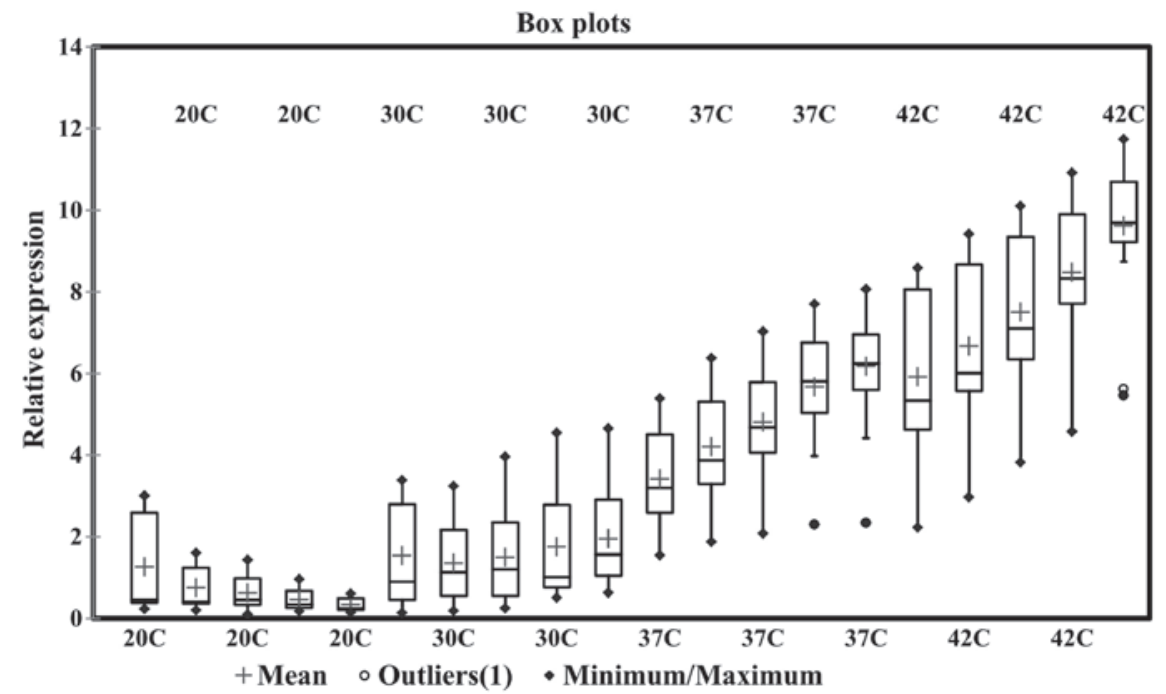

Figure 3. Box-whisker plot of heat shock protein 70 expression in the clinical and environmental groups at $20,30,37$ and $42^{\circ} \mathrm{C}$. The line in the box is the median, + indicates the mean, the box indicates the interquartile range, the box indicates the 25-75th percentile of the values and the whiskers indicate the minimum and maximum values. $\mathrm{C}$, celsius.

indicated that the sequence was also similar to its orthologous SSA4 gene in S. cerevisiae (69\% identity, $81 \%$ query coverage) and to the HSP70 gene in C.albicans (68\% identity, $83 \%$ query coverage). Other HSP70 subfamily genes (Ssb, Ssc, bipA, Kar2 and HscA) of A. fumigatus exhibited lower similarities to the yeast SSA4 gene sequence (data not shown).

By contrast, investigation of the HSP70 molecular regulation pathways rather than the genetics will indicate whether pre-exposure of yeast cells to stress can trigger a protective defense against subsequent exposure to the same stressor. Repeating thermal stimulation in a sequential-continuous manner, with a short duration of time between the two stimulations will result in a protective response. This phenomenon is driven by the transcription of protective stress-related genes and the accumulation of their mRNA or protein over a specified time in the cytoplasm as a form of molecular memory (30). In certain yeast species, an acquired thermotolerance phenomenon following continuous exposure to acute heat stress has been described (39-41).

Indeed, in eukaryotes, HSP (HSP90 and HSP70) expression is governed by HSF1 (31), which is highly conserved from yeast to human (42). However, unlike the well-determined Hsf1-dependent thermotolerance pathway in $S$. cerevisiae, the molecular interactions in the Hsf1-HSP70 axis in fungal pathogens such as A. fumigatus remain poorly understood.

In the present study, HSP70 expression levels in A.fumigatus isolates from clinical and environmental samples at 37 and $42^{\circ} \mathrm{C}$ were observed to increase continuously during the experimental days. The ascending pattern of HSP70 expression in both sample groups was relatively similar. The power of the association between the expression data obtained from the clinical and environmental samples was $>0.9$, indicating a strong correlation (Fig. 4). In both the sample groups, the greatest HSP70 mRNA levels were measured at $42^{\circ} \mathrm{C}$, and the highest significant increases in HSP70 expression were observed at $37^{\circ} \mathrm{C}$ (Table II). In the clinical groups, the mean relative expression level at $37^{\circ} \mathrm{C}$ was 2.7 times higher than the mean expression level at $30^{\circ} \mathrm{C}$, while in the environmental group this was 4.42 times. For both groups this was greatest increase in expression levels in comparison to the other temperature points. Furthermore, at $42^{\circ} \mathrm{C}$, HSP70 expression was markedly increased in the environmental samples, resulting in closer HSP70 levels (Table II). Overall these results indicate that 37 and $42^{\circ} \mathrm{C}$ are important temperature points able to induce HSP70 expression in A. fumigatus. These results are in accordance with similar studies indicating induced expression of HSP70 at high temperatures in yeast or mold fungi in particular, such as A. fumigatus $(7,11,43)$. It is important to note that in contrast to the present study, these previous studies were performed using short experimental durations, usually up to several hours following induction of heat stress, and that almost all have investigated heat shock-related genes within clinical or environmental groups separately.

In a previous study, HSP expression levels were evaluated up to several hours following a thermal shift from 30 to 37 and $48^{\circ} \mathrm{C}$, with the aim to understand the coregulatory association between metabolic and HSP genes in A.fumigatus. At early time points following heat induction, the lowest expression levels of HSPs were observed whereas metabolic genes were upregulated, from which the authors concluded that there is negative feedback between metabolic and HSP genes. However, the coherent feedforward loop association between the two groups of genes became weak with increasing temperature, and HSP expression exhibited a marked increase at $48^{\circ} \mathrm{C}$. From the three strains evaluated for HSP70 expression, two strains exhibited upregulation following $180 \mathrm{~min}$ at 37 and $48^{\circ} \mathrm{C}$ by a 2 - and 4 -fold increase in the expression ratio in a $\log 2$ scale, respectively. The one remaining strain showed downregulation (43). In an additional extensive investigation of A. fumigatus, HSP70 chaperone and additional genes in the HSP70 family were evaluated for alterations in expression levels in response to a temperature shift from 30 to $48^{\circ} \mathrm{C}$, in short time durations, from 30 to $180 \mathrm{~min}$. HSP70 chaperone exhibited a 2.45 -fold increase following a $180 \mathrm{~min}$ incubation at $48^{\circ} \mathrm{C}(11)$. Furthermore, a previous study evaluated temperature-induced protein synthesis in thermoresistant fungi including three samples of A. fumigatus. This indicated that 


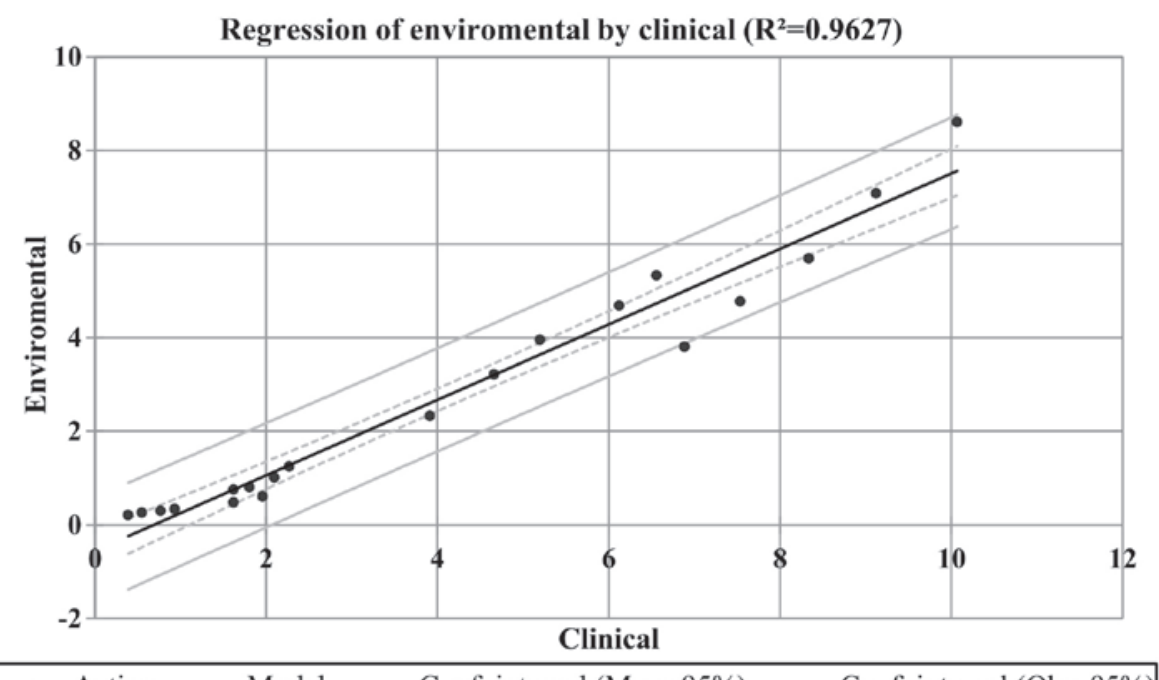

- $\quad$ Active - Model ---- Conf. interval (Mean 95\%) - Conf. interval (Obs. 95\%)

Figure 4. Regression analysis of the clinical and environmental data. The power of agreement between the expression levels of the clinical and environmental samples over the five experimental days is presented as a linear regression graph. $\mathrm{R}^{2}$, the adjusted $\mathrm{R}$ squared value, indicating the power of the association.

at $40^{\circ} \mathrm{C}$, medium- and high-molecular HSPs were synthesized while at $50^{\circ} \mathrm{C}$ no HSPs were detected (44).

It has been demonstrated that clinically isolated S. cerevisiae is able to grow at higher temperatures $\left(41^{\circ} \mathrm{C}\right)$ than laboratory isolates. Thermotolerance and growth ability at physiological temperatures is a critical requirement for the survival of $S$. cerevisiae strains in mice (45). This indicates that $S$. cerevisiae laboratory isolates were adapted to grow at lower temperatures rather than high temperatures $\left(41^{\circ} \mathrm{C}\right)$, however, by contrast clinical isolates tend to be more thermophilic than environmental isolates. In a previous study, southern blot patterns revealed extremely high genomic diversity and no clustering potential between clinical and environmental strains of A. fumigatus (46). Furthermore, a prior study of bovine aortic endothelial cells suggested that continuous heating at $42^{\circ} \mathrm{C}$ results in a continuous increasing trend of HSP70 expression over time ( $25 \mathrm{~h})$, although there were some reductions certain time points on the kinetic curve of HSP70 expression (47). Despite this, HSP expression trends remain a matter of debate, on account of complexities which have been noted by researchers. One study indicated that HSP expression in A. fumigatus is tightly negatively linked to fungal cell metabolic-related gene expression (43). When the fungus was incubated at high temperatures for short durations (60 and $120 \mathrm{~min}$ ), genes coding metabolic pathways were upregulated, however, the majority of the HSPs (other than HSP70) were downregulated. At 37 and $48^{\circ} \mathrm{C}$, two strains of A. fumigatus demonstrated induced levels of HSP70, however, one did not. Despite this, at $48^{\circ} \mathrm{C}$, the majority of HSPs showed a dramatic rise in expression levels, however, results obtained at $37^{\circ} \mathrm{C}$ indicate that temperatures such as those in the human body may be associated with reduced levels of certain HSPs, such as HSP30 (43). In addition, one of the first physiometabolic investigations on yeast HSP70 RNA levels indicated that HSP70 expression may vary in response to different physiological conditions of yeast cells (stationary phase at $23^{\circ} \mathrm{C}$ or sporulation phase at $30^{\circ} \mathrm{C}$ ). In the stationary phase, the majority of yeast HSP70-related RNAs reduced, however, the SSA3 RNA level was reversed by the addition of glucose (48).
However, the data of the current study supports the majority of prior findings, suggesting that HSP70 expression is increased following heat stress, in particular at $37^{\circ} \mathrm{C}$ or higher. In addition, the mentioned previous studies may be linked to the observations of the current study, which indicate low expression levels of HSP70 at temperatures below normal mammalian and human body temperature. Furthermore, previous observations may indicate that A. fumigatus, a frequently isolated filamentous fungus from extreme environments (49), may be adapted to ambient temperatures rather than physiological temperatures and host body conditions (43). This means that the environmental conditions in A. fumigatus induce a normal signal while host niches induce a stressed or abnormal signal to regulate HSPs. The majority of HSPs are upregulated in heat shock or when in contact with host serum components (50). The predominant source of air-borne spores of A. fumigatus are the decomposing remnants of plants and other organic debris, where fungi grow and release large number of spores into the atmosphere.

There are some obscurities in the observations of the current study. A downward trend of HSP70 expression levels was observed in clinical and environmental samples at $20^{\circ} \mathrm{C}$, however, in clinical samples HSP70 was upregulated on the first day of incubation at $20^{\circ} \mathrm{C}$. In addition, in the clinical group, HSP70 expression on the first day was higher than on the second day at $30^{\circ} \mathrm{C}$. The higher levels of HSP70 on the first day of incubation at 20 and $30^{\circ} \mathrm{C}$ may result from HSP70 mRNA remaining in the fungal cells from when they were in the host. The sudden shift from $37^{\circ} \mathrm{C}$ in the human body temperature (or higher in animals) to 20 or $30^{\circ} \mathrm{C}$ did not allow sufficient time for the fungus to downregulate HSP70 levels. It has been reported that fungal spores contain vacuoles with high amounts of HSPs and stored mRNAs belonging to various types of proteins in addition to HSPs $(11,51)$. Additionally, other explanation to these results may be the HSP induction due to cold-stress (52). In this regard, there are several reports on the induction of HSPs at low temperatures. Using S. cerevisiae, it has been demonstrated that the expression levels of certain HSPs, including HSP104p, HSP82p, HSP60p and HSP10p, were reduced in the first $2 \mathrm{~h}$ of 
the temperature downshift to $10^{\circ} \mathrm{C}$, in an early cold response. However, certain HSPs. including HSP12, HSP26, HSP42, $\mathrm{HSP} 104, \mathrm{YRO} 2$ and SSE2, were induced at $10^{\circ} \mathrm{C}$ for 12 and/or $60 \mathrm{~h}$ incubation, in a late cold response (52). Other similar reports have demonstrated that following longer durations of incubation (4-24 h) at low temperatures $\left(10,4\right.$ and $\left.0^{\circ} \mathrm{C}\right)$, certain HSPs were repressed while others were induced. It has been reported that following $4-24 \mathrm{~h}$ at $10^{\circ} \mathrm{C}$, HSP genes including HSP12, HSP26, HSP42, HSP104, SSA4, SSE2 and YRO2 were induced $(52,53)$. Additional genes in the HSP family including CIS3, HMS2, HSC82, HSP30, HSP60, HSP78, HSP82, HSP150, SSA1 and SSA2 demonstrated a downregulated trend when incubated at $10^{\circ} \mathrm{C}(53)$. However, their mRNA content recovered at lower temperatures (54). These observations indicate discrepancies which may be a matter of debate. For instance, the SSA4 and SSE2 genes were observed to be induced while SSA1 and SSA 2 were reduced at $10^{\circ} \mathrm{C}$. It appears that each HSP70 family of proteins may be regulated differentially in a time- and temperature-dependent manner (55).

In the present study, elevation of HSP70 expression in the later days at $30^{\circ} \mathrm{C}$ in the clinical sample was observed as positive feedback, and HSP70 re-upregulation following the depletion and consumption of the previously produced and accumulated HSPs, along with their associated mRNA. Furthermore, an explanation for the opposite HSP70 expression results in clinical and environmental samples at $30^{\circ} \mathrm{C}$ may be the adaptation of the clinical isolates to the host and therefore the loss of the host body's stimulatory factors. Potentially, clinical isolates have evolved to survive at high body temperatures in animals and humans, and adapted to the contact with host serum components and adverse conditions within the host body. It has been suggested that HSP90, which is associated with HSP70, orchestrates $C$. albicans yeast cells to transform to the filamentous form. This transition may be induced by two signals from the host body, the exposure to serum and the body temperature. Host body serum components including carbohydrates, metal ions and other nutrients may additionally be effective on HSP induction in fungal cells $(50,56-58)$. These adaptive mechanisms in clinical samples, particularly in response to temperature elevation, may explain the upregulation of HSP70 in clinical samples but the downregulation or lower expression levels in environmental samples, which was observed in the current study at 30,37 and $42^{\circ} \mathrm{C}$. In addition, another explanation for the lower $\mathrm{HSP} 70$ expression levels at $30^{\circ} \mathrm{C}$ in the environmental samples is the fact that the control strain (ATCC ${ }^{\circledR}$ 90906) was originally isolated from human blood. The standard strain was incubated at $25^{\circ} \mathrm{C}$ for five days as the control group. However, the environmental samples, which were incubated at $30^{\circ} \mathrm{C}$, demonstrated downregulation of HSP70. Therefore, the standard control strain may have acquired a partially similar gene expression profile to the clinical isolates. It should be noted that HSP70 expression at $30^{\circ} \mathrm{C}$ was increased significantly in comparison with the levels observed at $20^{\circ} \mathrm{C}$.

Overall, the results of the present study on the high expression ratios of HSP70 in A. fumigatus at 37 and $42^{\circ} \mathrm{C}$ are in agreement with previous reports. However, there are some limitations in estimating HSP gene expression, such as that HSP expression is suppressed at very high temperatures. This is also true for housekeeping (reference) genes which generally have been selected in gene expression quantification assays.
Gene expression of HSPs is not only dependent on heat stress or temperature shift but is also affected by other regulatory factors such as metabolic genes or other pathways which themselves are affected by additional stimuli or stresses. The multifactorial regulation of HSPs means that studies investigating stress-related gene expression are more complicated than other simple single-factor gene expression studies.

A. fumigatus is a known mesophilic fungus, however, has been shown to posses thermophilic traits in a number of studies. Regarding the reports indicating a direct association between thermotolerance and virulence, further knowledge on A. fumigatus pathogenesis associated with thermoresistance may result in the development of novel therapeutic approaches against this opportunistic pathogen. In the present study, the results indicated the increased expression pattern of HSP70 as a vital stress-related gene in A.fumigatus at high temperatures. In addition, the reported higher expression levels of HSP70 in clinical strains compared with environmental strains indicates a potential association between HSP70 expression and virulence in clinical strains of A.fumigatus. However, to gain further insight into the precise underlying molecular pathways and potential regulatory association between HSP70 and virulence, further studies are required.

\section{Acknowledgements}

The current study was supported by the Research Council of the University of Tehran.

\section{References}

1. Latgé JP: Aspergillus fumigatus and aspergillosis. Clin Microbiol Rev 12: 310-350, 1999.

2. Dagenais TR and KellerNP:Pathogenesis of Aspergillusfumigatus in invasive aspergillosis. Clin Microbiol Rev 22: 447-465, 2009.

3. Denning DW: Invasive aspergillosis. Clin Infect Dis 26: 781-803; quiz 804-805, 1998.

4. Gugnani HC: Ecology and taxonomy of pathogenic aspergilli. Front Biosci 8: s346-s357, 2003.

5. Fedorova ND, Nierman WC, Turner G, Joardar V, Maiti R, Anderson MJ, Denning DW, Wortman JR, Goldman GH and Osmani SA: A comparative view of the genome of Aspergillus fumigatus. In: The Aspergilli: Genomics, Medical Aspects, Biotechnology and Research Methods. Goldman GH and Osmani SA (eds.) CRC Press, Taylor \& Francis Group, pp25-38, 2008.

6. Lin SJ, Schranz J and Teutsch SM: Aspergillosis case-fatality rate: Systematic review of the literature. Clin Infect Dis 32: 358-366, 2001.

7. Nierman WC, Pain A, Anderson MJ, Wortman JR, Kim HS, Arroyo J, Berriman M, Abe K, Archer DB, Bermejo C, et al: Genomic sequence of the pathogenic and allergenic filamentous fungus Aspergillus fumigatus. Nature 438: 1151-1156, 2005.

8. Latgé JP: Aspergillus fumigatus and aspergillosis. Clin Microbiol Rev 12: 310-350, 1999.

9. Burnie JP, Carter TL, Hodgetts SJ and Matthews RC: Fungal heat-shock proteins in human disease. FEMS Microbiol Rev 30: 53-88, 2006.

10. Westerheide SD, Raynes R, Powell C, Xue B and Uversky VN: HSF transcription factor family, heat shock response, and protein intrinsic disorder. Curr Protein Pept Sci 13: 86-103, 2012.

11. Albrecht D, Guthke R,Brakhage AA and Kniemeyer O: Integrative analysis of the heat shock response in Aspergillus fumigatus. BMC Genomics 11: 32, 2010.

12. Inouye S, Katsuki K, Izu H, Fujimoto M, Sugahara K, Yamada S, Shinkai Y, Oka Y, Katoh Y and Nakai A: Activation of heat shock genes is not necessary for protection by heat shock transcription factor 1 against cell death due to a single exposure to high temperatures. Mol Cell Biol 23: 5882-5895, 2003.

13. Feige U and Polla BS: Hsp70-a multi-gene, multi-structure, multi-function family with potential clinical applications Experientia 50: 979-986, 1994. 
14. Feige U and Polla BS: Hsp70-a multi-gene, multi-structure, multi-function family with potential clinical applications. Experientia 50: 979-986, 1994.

15. Jolly C and Morimoto RI: Role of the heat shock response and molecular chaperones in oncogenesis and cell death. J Nat Cancer Inst 92: 1564-1572, 2000.

16. Allendoerfer R, Maresca B and Deepe GS Jr: Cellular immune responses to recombinant heat shock protein 70 from Histoplasma capsulatum. Infect Immun 64: 4123-4128, 1996.

17. Mayer MP and Bukau B: Hsp70 chaperones: Cellular functions and molecular mechanism. Cell Mol Life Sci 62: 670-684, 2005.

18. Owczarzy R, Tataurov AV, Wu Y, Manthey JA, McQuisten KA Almabrazi HG, Pedersen KF, Lin Y, Garretson J, McEntaggart NO, et al: IDT SciTools: A suite for analysis and design of nucleic acid oligomers. Nucleic Acids Res 36 (Web Server issue): W163-W169, 2008.

19. Schoonjans F, Zalata A, Depuydt CE and Comhaire FH: MedCalc: A new computer program for medical statistics. Comput Methods Programs Biomed 48: 257-262, 1995.

20. Livak KJ and Schmittgen TD: Analysis of relative gene expression data using real-time quantitative PCR and the 2 (-Delta Delta C (T)) Method. Methods 25: 402-408, 2001.

21. Zugel U and Kaufmann SH: Role of heat shock proteins in protection from and pathogenesis of infectious diseases. Clin Microbiol Rev 12: 19-39, 1999.

22. Tereshina VM: Thermotolerance in Fungi: The role of heat shock proteins and trehalose. Mikrobiologiia 74: 293-304, 2005 (In Russian).

23. Nicholls S, MacCallum DM, Kaffarnik FA, Selway L, Peck SC and Brown AJ: Activation of the heat shock transcription factor Hsf1 is essential for the full virulence of the fungal pathogen Candida albicans. Fungal Genet Biol 48: 297-305, 2011.

24. Brown AJ, Budge S, Kaloriti D, Tillmann A, Jacobsen MD, Yin Z, Ene IV, Bohovych I, Sandai D, Kastora S, et al: Stress adaptation in a pathogenic fungus. J Exp Biol 217: 144-155, 2014

25. Bhabhra R, Miley MD, Mylonakis E, Boettner D, Fortwendel J, Panepinto JC, Postow M, Rhodes JC and Askew DS: Disruption of the Aspergillus fumigatus gene encoding nucleolar protein CgrA impairs thermotolerant growth and reduces virulence. Infect Immun 72: 4731-4740, 2004.

26. Chang YC, Tsai HF, Karos M and Kwon-Chung KJ: THTA, a thermotolerance gene of Aspergillus fumigatus. Fungal Genet Biol 41: 888-896, 2004.

27. Dirr F, Echtenacher B, Heesemann J, Hoffmann P, Ebel F and Wagener J: AfMkk2 is required for cell wall integrity signaling, adhesion, and full virulence of the human pathogen Aspergillus fumigatus. Int J Med Microbiol 300: 496-502, 2010.

28. Wagener J, Echtenacher B, Rohde M, Kotz A, Krappmann S, Heesemann $\mathrm{J}$ and Ebel F: The putative alpha-1,2-mannosyltransferase AfMnt1 of the opportunistic fungal pathogen Aspergillus fumigatus is required for cell wall stability and full virulence. Eukaryot Cell 7: 1661-1673, 2008.

29. Zhou H, Hu H, Zhang L, Li R, Ouyang H, Ming J and Jin C: O-Mannosyltransferase 1 in Aspergillus fumigatus (AfPmt1p) is crucial for cell wall integrity and conidium morphology, especially at an elevated temperature. Eukaryot Cell 6: 2260-2268, 2007.

30. Leach MD, Tyc KM, Brown AJ and Klipp E: Modelling the regulation of thermal adaptation in Candida albicans, a major fungal pathogen of humans. PLoS One 7: e32467, 2012.

31. Leach M and Cowen L: To sense or die: Mechanisms of temperature sensing in fungal pathogens. Curr Fungal Infect Rep 8: 185-191, 2014.

32. Metzger MB and Michaelis S: Analysis of quality control substrates in distinct cellular compartments reveals a unique role for Rpn $4 \mathrm{p}$ in tolerating misfolded membrane proteins. Mol Biol Cell 20: 1006-1019, 2009

33. Geiler-Samerotte KA, Dion MF, Budnik BA, Wang SM, Hartl DL and Drummond DA: Misfolded proteins impose a dosage-dependent fitness cost and trigger a cytosolic unfolded protein response in yeast. Proc Natl Acad Sci USA 108: 680-685, 2011.

34. Satyanarayana C, Schröder-Köhne S, Craig EA, Schu PV and Horst M: Cytosolic Hsp70s are involved in the transport of aminopeptidase 1 from the cytoplasm into the vacuole. FEBS Lett 470: 232-238, 2000.

35. Daugaard M, Rohde $M$ and Jäättelä $M$ : The heat shock protein 70 family: Highly homologous proteins with overlapping and distinct functions. FEBS Lett 581: 3702-3710, 2007.
36. Verghese J, Abrams J, Wang Y and Morano KA: Biology of the heat shock response and protein chaperones: Budding yeast (Saccharomyces cerevisiae) as a model system. Microbiol Mol Biol Rev 76: 115-158, 2012

37. Bonner JJ, Carlson T, Fackenthal DL, Paddock D, Storey K and Lea K: Complex regulation of the yeast heat shock transcription factor. Mol Biol Cell 11: 1739-1751, 2000.

38. Cerqueira GC, Arnaud MB, Inglis DO, Skrzypek MS, Binkley G, Simison M, Miyasato SR, Binkley J, Orvis J, Shah P, et al: The Aspergillus genome database: Multispecies curation and incorporation of RNA-Seq data to improve structural gene annotations. Nucleic Acids Res 42 (Database Issue): D705-D710, 2014.

39. De Virgilio C, Simmen U, Hottiger T, Boller T and Wiemken A: Heat shock induces enzymes of trehalose metabolism, trehalose accumulation, and thermotolerance in Schizosaccharomyces pombe, even in the presence of cycloheximide. FEBS Lett 273: 107-110, 1990.

40. Piper PW: Molecular events associated with acquisition of heat tolerance by the yeast Saccharomyces cerevisiae. FEMS Microbiol Rev 11: 339-355, 1993.

41. Argüelles JC: Thermotolerance and trehalose accumulation induced by heat shock in yeast cells of Candida albicans. FEMS Microbiol Lett 146: 65-71, 1997.

42. Wu C: Heat shock transcription factors: Structure and regulation. Annu Rev Cell Dev Biol 11: 441-469, 1995.

43. Do JH, Yamaguchi R and Miyano S: Exploring temporal transcription regulation structure of Aspergillus fumigatus in heat shock by state space model. BMC Genomics 10: 306, 2009.

44. Chen KU and Chen ZC: Heat shock proteins of thermophilic and thermotolerant fungi from Taiwan. Bot Bull Acad Sin 45 247-257, 2004.

45. McCusker JH, Clemons KV, Stevens DA and Davis RW: Saccharomyces cerevisiae virulence phenotype as determined with CD-1 mice is associated with the ability to grow at 42 degrees $\mathrm{C}$ and form pseudohyphae. Infect Immun 62: 5447-5455, 1994.

46. Debeaupuis JP, Sarfati J, Chazalet V and Latgé JP: Genetic diversity among clinical and environmental isolates of Aspergillus fumigatus. Infect Immun 65: 3080-3085, 1997.

47. Wang S, Diller KR and Aggarwal SJ: Kinetics study of endogenous heat shock protein 70 expression. J Biomech Eng 125: 794-797, 2003.

48. Werner-Washburne M, Becker J, Kosic-Smithers J and Craig EA Yeast Hsp70 RNA levels vary in response to the physiological status of the cell. J Bacteriol 171: 2680-2688, 1989.

49. Tepšič K, Gunde-Cimerman N and Frisvad JC: Growth and mycotoxin production by Aspergillus fumigatus strains isolated from a saltern. FEMS Microbiol Lett 157: 9-12, 1997.

50. Shapiro RS, Uppuluri P, Zaas AK, Collins C, Senn H, Perfect JR, Heitman J and Cowen LE: Hsp90 orchestrates temperature-dependent Candida albicans morphogenesis via Ras1-PKA signaling. Curr Biol 19: 621-629, 2009.

51. Low SY, Dannemiller K, Yao M, Yamamoto N and Peccia J: The allergenicity of Aspergillus fumigatus conidia is influenced by grow th temperature. Fungal Biol 115: 625-632, 2011.

52. Schade B, Jansen G, Whiteway M, Entian KD and Thomas DY: Cold adaptation in budding yeast. Mol Biol Cell 15: 5492-5502, 2004.

53. Sahara T, Goda $\mathrm{T}$ and Ohgiya S: Comprehensive expression analysis of time-dependent genetic responses in yeast cells to low temperature. J Biol Chem 277: 50015-50021, 2002.

54. Murata Y, Homma T, Kitagawa E, Momose Y, Sato MS, Odani M, Shimizu H, Hasegawa-Mizusawa M, Matsumoto R, Mizukami S, et al: Genome-wide expression analysis of yeast response during exposure to 4 degrees C. Extremophiles 10: 117-128, 2006.

55. Aguilera J, Randez-Gil F and Prieto JA: Cold response in Saccharomyces cerevisiae: New functions for old mechanisms. FEMS Microbiol Rev 31: 327-341, 2007.

56. Berman J and Sudbery PE: Candida albicans: A molecular revolution built on lessons from budding yeast. Nat Rev Genet 3: 918-930, 2002

57. Swoboda RK, Bertram G, Budge S, Gooday GW, Gow NA and Brown AJ: Structure and regulation of the HSP90 gene from the pathogenic fungus Candida albicans. Infect Immun 63: 4506-4514, 1995

58. Zeuthen ML and Howard DH: Thermotolerance and the heat-shock response in Candida albicans. J Gen Microbiol 135: 2509-2518, 1989. 